\title{
THE THEORY AND PRACTICE OF DISCLOSING HMO PHYSICIAN INCENTIVES
}

\author{
MARK A. HALL* \\ I \\ INTRODUCTION
}

Law professors, as a whole, are rather worldly and cynical about financial, political, and other suspect forms of motivation. I was therefore surprised to find that, as managed care was taking hold in the early 1990s, several of my colleagues were genuinely startled to learn that Health Maintenance Organizations ("HMOs") commonly reward physicians for saving costs, which often entails withholding care. My colleagues first learned of this when my university required all of its employees to switch from Blue Cross insurance to its own newly established HMO, created to keep the University's physicians and affiliated hospital from losing business. As the resident expert on managed care, I was peppered for several months with anxious questions and angry comments about this change. The reaction that most surprised me was the dismay over learning that our HMO, like most others, uses a risk pool to reward its physicians for staying within budget. My colleagues wanted to know how long HMOs had been doing this and why they had not heard about it before.

In a recent commentary, health economist James Robinson observed that "the fundamental flaw of managed care, in retrospect, was that it sought to navigate the tensions between limited resources and unlimited expectations without explaining exactly how it was so doing." As my experience reflects, this is certainly true for HMOs' use of physician incentives, one of managed

Copyright (C) 2002 by Mark A. Hall

This article is also available at http://www.law.duke.edu/journals/65LCPHall.

* Fred D. and Elizabeth L. Turnage Professor of Law and Public Health, Wake Forest University. In the spirit of full disclosure, I occasionally do consulting work for a law firm that represents several large Health Maintenance Organizations ("HMOs"). Much of the work reflected in this paper was completed pursuant to a grant from the Robert Wood Johnson Foundation, although the analysis and conclusions do not necessarily represent the Foundation's views. I wish to thank the following colleagues for their support and assistance: Beth Dugan, Raj Balkrishnan, Don Bradley, Beiyao Zheng, Kristin Kidd, and Aneil Mishra.

1. James C. Robinson, The End of Managed Care, 285 JAMA 2622, 2623 (2001). More acerbically, George Anders has commented that "HMOs don't present themselves as the medical equivalent of a tawdry motel chain or a discount clothing store in a rundown part of town, blithely selling an inferior product in the name of having the cheapest possible price. Managed-care companies promise to uphold standards through their cost cutting, simply by targeting wasteful practices." GeOrge ANDERs, HeAlth Against WeAlth: HMOs AND THE BREAKDOWN OF MEDiCAL TRUST 59 (1996). 
care's major tools. HMOs routinely pay physicians in a manner that rewards them for saving costs, ${ }^{2}$ in sharp contrast with the inflationary incentives of traditional fee-for-service reimbursement. Other features of managed care are visible to all members, such as a limited network of providers, primary care gatekeeping, or prior authorization requirements. Physician incentives, however, are entirely behind the scenes.

Elsewhere in this symposium, HMOs are faulted for failing to justify their overall cost-containment mission or their more visible cost-containment techniques. But at least these aspects of managed care are generally known to consumers. Regarding financial incentives, most HMOs until recently have made no effort even to call these to people's attention, much less justify their use. Disclosure of financial incentives to consumers has occurred only in the past three years, in response to several legal pressures. The nondisclosure of incentives is a major focus in the legal attack against the HMO industry mounted by the class action lawsuits discussed elsewhere in this volume. ${ }^{3}$ The presence of undisclosed financial incentives is also being used by plaintiffs' lawyers in more garden-variety tort suits to help establish breach of a duty of care or to make a case for punitive damages. ${ }^{4}$ And patient protection legislation adopted recently in many states, and proposed in Congress, requires HMOs to disclose their physician payment methods.

These developments call for an assessment of the theory and practice of disclosing physician incentives. To what extent does the earlier silence of HMOs about physician incentives account for the public's backlash against managed care and the failure to appreciate the need for making cost/benefit trade-offs in medicine? Now that disclosure is becoming more commonplace, will this increase the public's acceptance of HMOs, or will it further undermine trust? Will anyone even notice? To gain better understanding of these issues, this article begins by summarizing the theoretical case for mandating disclosure of

2. Payment typically occurs in two basic forms. Capitation payments pay physicians a fixed amount for each patient for whom they are responsible, regardless of the costs of care. Capitation comes in various forms depending on what portion of services it covers (for example, primary care, specialist referrals, or hospitalization). Alternatively, HMOs can create a "withhold pool" or "risk pool" that makes a portion of a physician's payment contingent on whether the physician meets budgetary goals. See generally T.S. Bodenheimer and K. Grumbach, Capitation or Decapitation: Keeping your Head in Changing Times, 276 JAMA 1025 (1996); Marsha Gold et al., Behind the Curve: A Critical Assessment of How Little is Known About Arrangements Between Managed Care Plans and Physicians, 52 MED. CARE RES. REV. 307 (1995); H.T. Greely, Direct Financial Incentives in Managed Care: Unanswered Questions, 6 HeAlth MATRIX 53 (1996); D. Orentlicher, Paying Physicians More to Do Less: Financial Incentives to Limit Care, 30 U. RICH. L. REV. 155 (1996); Steven D. Pearson et al., Ethical Guidelines for Physician Compensation Based on Capitation, 339 N. ENGL. J. MED. 689 (1998).

3. See Gail R. Agrawal \& Howard R. Veit, Back to the Future: The Managed Care Revolution, 65 LAW \& CONTEMP. PROBS. 11 (Autumn 2002); Clark C. Havinghurst, How the Health Care Revolution Fell Short, 65 LAW \& CONTEMP. PROBS. 55 (Autumn 2002).

4. See infra text accompanying notes 31-32.

5. For an overview of state law, see Tracy E. Miller \& William M. Sage, Disclosing Physician Financial Incentives, 281 JAMA 1424-30 (1999). The current federal bills require disclosure only upon request, as under Medicare. S. 1052, 107th Cong. § 121(c)(2) (2001); H.R. 2563, 107th Cong. § 121(c)(2) (2001). 
incentives, in terms of various types of information market failures. The article then analyzes the components of liability and regulatory law that require disclosure, observing how well each source of law responds to different aspects of the justification for disclosure. Following this, empirical literature is explored on the content, source, and timing of disclosures now being made, and on the impact of incentive disclosures. The article concludes by sketching a model approach to disclosure, one that provides information in layers, at different points, and in varying levels of detail, as best suits people's desire and need for information.

II

\section{THE CASE FOR MANDATORY Disclosure}

\section{A. Reasons for Incentive Disclosure}

In his comprehensive analysis of the disclosure of health-related information, William Sage presents three separate rationales for disclosing physician incentives: promoting competition, reducing agency problems, and enhancing social awareness. ${ }^{6}$ Disclosing physician incentives promotes competition by heightening focus on whether HMOs are using appropriate incentives and by stimulating innovation in new types of incentives. For example, the market has evolved in the past few years away from incentives addressed exclusively to cost-saving and more toward mixed incentives that reward both cost-saving and improved performance. Blue Cross/Blue Shield of California recently announced with much fanfare that it is dropping cost-containment incentives altogether in favor of incentives that reward higher patient satisfaction and greater use of preventive health services. ${ }^{7}$ PacifiCare also announced that it would reward physicians for holding down patients' out-of-pocket costs (for copayments and prescription drugs, for instance) rather than holding down total medical costs. ${ }^{8}$ These policy shifts appear to be stimulated by increased public awareness of incentives and competitors' desires to formulate more appealing types of incentives.

Incentive disclosure also reduces agency problems by addressing the conflict of interest that can arise when physicians are rewarded for reducing costs.' Short of banning such incentives, disclosure puts patients on notice that their physicians may be influenced by payment methods, which allows patients to

6. William Sage, Regulating Through Information: Disclosure Laws and American Health Care, 99 COLUM. L. REV. 1701 (1999) [hereinafter Sage, Regulating Through Information].

7. Blue Cross of California to Base Physician Incentives on Quality of Care, 10 HEALTH L. REP. (BNA) 1104, 1104 (2001).

8. Cheryl Jackson, HMO Ties Bonuses to Saving Patients Money, AM. MED. News, Aug. 13, 2001, at 20; see also Jennifer Powell, HMO Deal May Create Precedent: Harvard Pilgrim's Pact with Partners Links \$\$, Quality-of-Care Goals, BostON HERALD, June 20, 2001, at 31 (reporting an HMO's agreement to reward a hospital network for improving its quality of care).

9. See Mark A. Hall, Motivating Physicians Through Financial Incentives: An Agency Theory Perspective, in PHYSICIAN CONFLICTS OF INTEREST 228 (R. Spece et al. eds., 1997). 
better look after their own interests when evaluating a physician's treatment recommendations. Also, if disclosure occurs at the right time and with sufficient options, it can present the opportunity either to consent to or to refuse such incentives, which gives these ethically troubling incentives greater legitimacy. ${ }^{10}$ Furthermore, disclosure has a cautionary impact on physicians by deterring them from agreeing to accept payment methods that they would not be comfortable acknowledging and discussing with their patients. ${ }^{11}$

Most relevant to this symposium, disclosure of incentives serves the more public purpose of educating health care consumers about the need to constrain health care spending and the trade-offs among competing methods for doing so. Incentive disclosure is an opportunity to explain the inflationary incentives of traditional fee-for-service reimbursement, the potential harms of overtreatment, and the common stake that everyone has in keeping health insurance affordable. Disclosure can also be done in a fashion that compares different types of cost-control mechanisms, by observing that using physician incentives may be preferable to forcing patients to pay for more of their medical costs out of pocket or to setting inflexible, across-the-board limits on what insurance will cover. $^{12}$ Although these points are fundamental to health care policy and to how health insurance is currently financed, they are not widely appreciated because our understanding and expectations of health insurance were formed during the era of unconstrained indemnity insurance.

\section{B. Making Disclosure Mandatory}

Having good reasons for disclosure, however, is not sufficient justification to legally mandate it. Economic theory predicts that properly functioning markets will produce roughly the types of information that consumers need in order to make adequately informed purchasing decisions. ${ }^{13}$ Imperfections in the market production of consumer information certainly can be expected, and the relative costs and benefits of perfecting product information can be debated. If a category of information is entirely absent, however, one must ask, before mandating its disclosure, whether the information is important and why the market has failed to produce it. If knowledge about physician payment methods is in fact an important piece of consumer information, one would expect consumers to inquire, or insurers to advertise, about this component of managed care. This is true even if the relevant information is negative, since firms that do better are

10. See Mark A. Hall, Making Medical Spending Decisions: The Law, Ethics, and ECONOMICS OF RATIONING MECHANISMS 193-224 (1997) [hereinafter HALl, MEDICAL SPENDING DECISIONS].

11. See Mark A. Hall, Managed Care Medical Ethics: A Dose of Realism, 128 ANN. InTERn. MED. 395, 398 (1998) [hereinafter Hall, A Dose of Realism]; Sage, Regulation Through Information, supra note 6 , at 1770 .

12. See generally Hall, Medical Spending Decisions, supra note 10. For an example of this type of disclosure see also Appendix B.

13. Wesley Magat, Information Regulation, in 2 THE NeW PALGRAVE Dictionary OF ECONOMICS AND THE LAW 302, 302 (Peter Newman ed., 1998). 
well-motivated to tout their superiority. ${ }^{14}$ At least by inference, consumers will assume that firms that are silent on a potentially negative point have something to hide, which tends to force all but the most negative firms to reveal their attributes regarding the pertinent issue.

Mandating disclosure unnecessarily, either when it would occur naturally or when the information is not actually relevant to consumers' decisions, could impose several costs beyond the trivial costs of releasing the information. Cluttering consumer information with irrelevant and distracting detail makes it more difficult to focus on the information consumers find truly important, which detracts from the ultimate economic goal of disclosure. Also, because governmental mandates tend to be uniform and difficult to modify, they may lock into place a form or content of disclosure that is suboptimal. A government mandate runs the risk of delivering the wrong type or quantity of information, in the wrong format, and at the wrong time. Therefore, further reflection is needed to establish more firmly the justification for mandatory disclosure laws.

Three types of market failure potentially justify mandating disclosure of physician incentives. ${ }^{15}$ Each of these market failures affects other aspects of managed care; therefore, this explanation goes a long way toward advancing understanding of why HMOs have failed to achieve their potential in the other arenas explored in this symposium. ${ }^{16}$ The first and most fundamental form of market failure exists in the disjunction between who pays for health insurance and who consumes it. The market forces that shape disclosure practices are driven primarily by employers, because they are the ultimate purchasing decision-makers that health insurers need to woo. ${ }^{17}$ Physician incentives are much less relevant to employers' decisions, however, or are relevant in different ways, than they are to the ultimate consumers of health care because the agency problems created by physician conflicts of interest affect patients, not purchasers. Purchasers tend to be concerned with how well cost-containment methods work, but not especially concerned about the particular methods. ${ }^{18}$ Therefore, a competitive market driven by employer purchasing decisions is not likely to produce the types of information that patients desire. This point holds not only for physician incentives, but also for many other types of information about health insurance. This market distortion is caused by the tax and regulatory

14. Michael Fishman \& Kathleen Hagerty, Mandatory Disclosure, in 2 THE New PALGRAVE DICTIONARY OF ECONOMICS AND THE LAW 605, 605 (Peter Newman ed., 1998).

15. See John C. Coffee, Jr., Market Failure and the Economic Case for a Mandatory Disclosure System, 70 VA. L. REV. 717, 751-53 (1984).

16. See Frank A. Sloan \& Mark A. Hall, Market Failures and the Evolution of State Regulation of Managed Care, 65 LAW \& CONTEMP. PROBS. 169 (2002).

17. David A. Hyman \& Mark A. Hall, Two Cheers for Employment-Based Health Insurance, 2 YALE J. HeAlTH POL’y L. \& ETHICs 23, 27-28 (2002).

18. See Gail Agrawal, Resuscitating Professionalism: Self-Regulation in the Medical Marketplace, 66 U. Mo. L. REV. 341, 370-71 (2001). 
policies that favor employer-based insurance, ${ }^{19}$ but, for other reasons, it does not make sense to abandon or radically alter this system..$^{20}$ Therefore, the second-best option is to mandate disclosure of the types of information that a purer market would likely generate..$^{21}$

Second, an application of what is known as the "lemons" phenomenon undermines the ability of even a fully competitive market from generating important consumer information. The "lemons" phenomenon, which is generalized from the automobile market, holds whenever product information is difficult to verify independently. ${ }^{22}$ In these circumstances, competitive markets tend to suppress rather than generate the information because it is difficult for producers to convince consumers that they provide better value at a higher price. ${ }^{23}$ Without the ability to compare, consumers assume the worst about all producers, and therefore are willing to pay only for lower quality goods or services. The market-clearing price, or equilibrium, settles at a suboptimal level that will not support higher quality, even when some or many purchasers would be willing to pay for more. In the present context, a version of this type of market failure exists because of the difficulty in determining physician payment methods without disclosure. Payment methods cannot be directly observed, in contrast with other cost-containment tools. Many HMOs regard them as trade secrets, and physicians can be prohibited by contract from revealing them. Insurers willing to reveal that they use superior forms of incentives therefore have a difficult time convincing consumers that this is true, since comparative information is difficult to ferret out without mandatory disclosure.

Finally, incentive disclosure suffers from a classic public goods or collective action problem. When many of the costs or benefits of a product extend far beyond the parties to an immediate transaction, the good will be produced at suboptimal levels, because the incentives affecting individual producers or consumers are poorly matched to broader social welfare. Public education is a classic example. Education here takes the form of raising general public awareness of the need to contain health care costs and the merits and drawbacks of competing approaches. Willingness to pay for this information is a public goods problem, although perhaps a trivial one. More significantly, insurers' willingness to bear the reputational costs of supplying this information is a collective action problem. The industry as a whole may realize that there is a collective advantage to lowering public expectations about the ability of insurance to fund health care as if costs were never a legitimate consideration. No single insurer,

19. See generally MARK PAUly, HeAlth Benefits At WORK: An ECONOMIC AND POLITICAL ANALYSIS OF EMPLOYMENT-BASED HEALTH INSURANCE (1997).

20. Hyman \& Hall, supra note 17, at 30-41.

21. For a similar argument relating to mandatory disclosure in the securities market, see Paul Mahoney, Mandatory Disclosure as a Solution to Agency Problems, 62 U. CHI. L. REV. 1047, 1048-52 (1995).

22. George A. Akerloff, The Market for Lemons: Quality Uncertainty and the Market Mechanism, 84 Q. J. ECON. 488 (1970); see also Cal. Dental Assoc. v. FTC, 526 U.S. 756, 771-72 (1991) (discussing information problems that affect health care markets).

23. Eric Talley, Disclosure Norms, 149 U. PA. L. REV. 1955, 1997-98 (2001). 
however, would view it as an advantage to its competitive stance to be the first to break the bad news. Collectively, insurers appear willing to be more candid about the less appealing aspects of their cost containment objectives, so long as there is some assurance that all insurers will do so. Absent compulsion, however, this assurance simply is not available. Instead, pack mentality leads insurers to stress only the positive aspects of managed care. This distortion is built into the very name the industry has embraced for its product: the positivesounding term "health maintenance." Individual HMOs employ similarly happy monikers for their company names. ${ }^{24}$

This dissection of market imperfections is more than just an academic exercise to justify the legal and policy decision to mandate disclosure. Each type of market failure is distinct, each aligns with one of the three economic and social purposes of incentive disclosure outlined above, and each type points to different ways in which disclosure should be mandated. The "lemons" imperfection relates most strongly to the simple competitive function of disclosure-one that informs in order to spark the competitive forces that shape development of superior physician incentives. One simple solution to the "lemons" imperfection is to remove the obstacles to verifying incentives in use. This might consist of banning so-called "gag clauses," which is now universally the law; ${ }^{25}$ requiring that physician incentives be reported to government regulators as is required for Medicare HMOs, ${ }^{26}$ and declaring that the general structure of physician payment methods is not a legitimate trade secret. These measures should be sufficient to allow incentive information to come forward in the form and to the extent that it is relevant to market transactions.

The market imperfection created by employers' purchase of health insurance, however, requires further measures to address the purpose of promoting an effective agency relationship. Insurers might be required actively to inform consumers of their physician payment methods prior to choosing insurance, or physicians might be required to reveal financial conflicts of interest at the point at which patients are evaluating physicians' treatment recommendations. If, however, disclosure is motivated by ethical concerns over how incentives might affect physician judgment, requiring physicians to disclose incentives at the point of treatment might be exactly the wrong method, since this forces physicians to call to mind the very conflicting incentive that we would like physicians to ignore. ${ }^{27}$ Instead, disclosure might better occur when patients first sign up with a physician and periodically thereafter, regardless of any pending treatment decisions. Such disclosures might not require great detail about the tech-

24. For instance, Wake Forest University's home-grown HMO is named "QualChoice." Similarly, the HMO created by Duke University was named "Wellpoint."

25. Joan H. Krause, The Brief Life of the Gag Clause: Why Anti-Gag Clause Legislation Isn't Enough, 67 TENN. L. REV. 1 (1999).

26. Physician Incentive Payments, 42 C.F.R. $\S 417.479(\mathrm{~h})(3), \S 434.70$.

27. See Mark A. Hall, A Theory of Economic Informed Consent, 31 GA. L. REV. 511, 526 (1997) [hereinafter Hall, Economic Informed Consent]. 
nical aspects of payment methods. As discussed more fully below, ${ }^{28}$ it could be sufficient, under some rationales, simply to describe the existence and general orientation of physician incentives, rather than to insist on disclosures that amount to warnings, ${ }^{29}$ as occurs for potential product defects or under informed consent law.

The educative purpose, which suffers most directly from the collective action or public goods imperfection, points to a very different type of disclosure. This purpose could be advanced by disclosing incentives after purchasing insurance, and apart from any discrete decision about treatment or insurance selection. The content of disclosure would be oriented more toward explaining or justifying incentives, rather than simply describing them or issuing warnings.

In sum, the different theoretical purposes for disclosing financial incentives point toward disclosures of distinctly different content, sources, and timing. To learn which of these theories and practices are the prevailing ones, we next examine the sources of law that currently require disclosure. This discussion will be followed by a description and analysis of how HMOs currently disclose physician incentives and a review of empirical evidence about the effects of these disclosures.

III

\section{LEGAL MECHANISMS FOR MANDATING DisClOSURE}

\section{A. Liability for Nondisclosure}

Disclosure can be mandated through two basic legal mechanisms: liability and regulation..$^{30}$ A variety of tort law theories is being used to impose liability on HMOs for failing to disclose incentives. In medical malpractice cases, plaintiffs' lawyers are seeking to hold HMOs responsible for physicians' negligence by arguing that a physician's departure from the standard of care was caused by an HMO's undisclosed incentive plan, ${ }^{31}$ and that undisclosed incentives are grounds for imposing punitive damages. ${ }^{32}$ Legal theorists have argued that fail-

28. See infra text accompanying notes 85-91.

29. See infra text accompanying notes $92-99$.

30. Disclosure of financial conflicts of interest is also required by medical and institutional ethics authorities. See L. McCullough, A Basic Concept in the Clinical Ethics of Managed Care: Physicians and Institutions as Economically Disciplined Moral Co-Fiduciaries of Populations of Patients, $24 \mathrm{~J}$. MED. \& PHILO. 77 (1999).

31. See infra note 54.

32. The most notorious example is Fox v. Health Net, in which a California jury awarded $\$ 77$ million in punitive damages in a breach of contract action against an HMO that had refused to pay for an innovative cancer treatment, which the surviving family claimed resulted in the patient's death. The verdict was reportedly affected by the fact that the HMO's medical director was paid in a fashion that rewarded him in proportion to the number of claims he turned down. No. 219624, 1993 WL 794305 (Cal. Super. Ct. Dec. 23, 1993). See Allison Walsh, The Legal Attack on Cost Containment Mechanisms, 31 J. MARSHALL L. REV. 207, 232 (1997). 
ure to disclose incentives can form the basis of informed consent liability, ${ }^{33}$ although so far this particular argument has not succeeded in the courtroom. ${ }^{34}$ The failure to disclose incentives is at the heart of the class action suits pending against each of the major HMOs. ${ }^{35}$ Nondisclosure is claimed to be a species of fraud giving rise to a RICO violation, and it is claimed to be a breach of fiduciary duty under ERISA. The ERISA fiduciary claim was given more prominence by a passing reference in the Supreme Court's opinion in Pegram v. Herdrich $^{36}$ Similar fraud and fiduciary claims have also been made under state common law. ${ }^{37}$

Depending on the particular legal theory used and the consequences of finding a violation, the threat of liability might result in widely different disclosure formats that vary in source, content, and timing. A tort law theory is likely to focus on whether the disclosure was made in the context of a treatment decision, rather than in the context of choosing or enrolling in a health plan, since the relevant issue is how the disclosure allegedly relates to a bad medical outcome. A fraud theory is likely to focus on disclosure by the health plan, rather than by the physician, because the health plan is the source of the incentive, and it is the insurance product that is arguably devalued by the existence of the incentive. To avoid a fraud accusation, the disclosure ostensibly should occur prior to or at the time of insurance purchase. A fiduciary theory presents a hybrid case. It might be relevant either to insurance purchase or to medical treatment, and to both a physician and a health plan. Fiduciary obligations could be satisfied at points in time other than the immediate context of deciding about treatment or insurance purchase. For instance, disclosure might occur following enrollment in the health plan, or at the point at which a patient first selects a primary care physician, since the information relates to a patient's overall and ongoing relationship with the plan and the provider. Thus, liability theories send inconsistent messages about who should be making incentive disclosures and when they should occur.

33. Joan H. Krause, Reconceptualizing Informed Consent in an Era of Health Care Cost Containment, 85 IOWA L. REV. 261, 264 (1999); Susan M. Wolf, Toward a Systemic Theory of Informed Consent in Managed Care, 35 Hous. L. REV. 1631, 1632 (1999).

34. See Hall, Economic Informed Consent, supra note 27, at 582-83; Krause, supra note 33, at 376.

35. See, e.g., Maio v. Aetna, 221 F.3d 472, 474 (3d Cir. 2000); In re Managed Care Litig., No. 001334-MD-MORENO, 2001 U.S. Dist. LEXIS 14501, at*1. (S.D. Fla. June 29, 2001).

36. Pegram v. Herdrich, 530 U.S. 211, 227 n.8 (2000) (holding that the existence of physician incentives does not state a claim for breach of ERISA fiduciary duties, but noting that the plaintiff had failed to preserve a claim for failing to disclose such incentives, which might constitute a fiduciary breach). This ERISA theory was accepted in Shea v. Esensten, 107 F.3d 625,626 (8th Cir. 1997), but rejected in Ehlmann v. Kaiser Found. Health Plan, 198 F.3d 552, 553 (5th Cir. 2000). See generally Richard D. Leigh, Physician Incentives and ERISA Fiduciary Liability after Pegram v. Herdrich: What Solutions are Available to HMO Patients Harmed by Non-disclosure of Incentive Compensation Schemes?, 106 DICK. L. REV. 415 (2002).

37. See, e.g., Shea v. Esensten, 208 F.3d 712, 716-17 (8th Cir. 2000) (stating in dictum that a fiduciary claim is available under Minnesota law); Neade v. Portes, 739 N.E.2d 496, 499 (Ill. 2000) (rejecting a fiduciary claim). See generally Peter D. Jacobson \& Michael T. Cahill, Applying Fiduciary Responsibilties in the Managed Care Context, 26 AM. J.L. \& MED. 155 (2000). 
The content of incentive disclosure also varies widely depending on the particular theory of liability. Under most liability theories, it should be sufficient simply to provide bare notice of financial incentives in terms that describe their general structure and direction. This is all that is required in other fiduciary contexts such as legal representation and financial dealings. ${ }^{38}$ Elsewhere, there is no precedent for requiring a full articulation of all components of compensation systems and their possible effects. ${ }^{39}$ For instance, it is generally considered sufficient for legal representation that the client know simply whether a lawyer is paid by the hour or on a contingency fee basis, and the relevant rates. Likewise, for a real estate agent or a financial advisor, typically all that one is told, if anything, is that they are paid a commission of a certain size. It is obvious in what direction these incentives point. Statistics and examples of how events might go badly could increase understanding, but they are not required, nor are they routinely given. Similarly, in medicine, under most liability theories it should be sufficient to be told that, in contrast with fee-for-service incentives, a physician is paid in a way that encourages savings costs.

Much more extensive disclosure might be required, however, under an extension of informed consent theory, which has its roots in fiduciary principles. Under informed consent law as it has developed in many states, it can be argued that all factors that are relevant to a treatment decision must be disclosed in as much detail as a reasonable patient might desire to fully inform her evaluation of a physician's treatment recommendation. ${ }^{40}$ The higher level of disclosure and understanding might also be required if disclosure were being used not simply to avoid liability for failure to disclose but instead as an affirmative defense in a negligence case asserting that a patient had agreed to accept a lower standard of care. The extent to which providers disclose the medical risks of treatment illustrate how extensive the resulting financial disclosures might be, if prompted by the threat of informed consent liability. Although informed consent law has not yet been applied in this fashion to cost-containment financial incentives, ${ }^{41}$ several commentators argue that it should be. ${ }^{42}$ To be completely safe from legal challenge, incentive disclosures might need to include not only detailed

38. See Saul Levmore, Commissions and Conflicts in Agency Arrangements: Lawyers, Real Estate Brokers, Underwriters, and Other Agents' Rewards, 36 J.L. \& ECON. 503 (1993).

39. Mark A. Hall, Rationing Health Care at the Bedside, 69 N.Y.U. L. REV. 693, 777-80 (1994); L.S. Sealy, Some Principles of Fiduciary Obligations, CAMBRIDGE L. J. 119 (1963).

40. This is the so-called "patient-centered" standard, which stands in contrast to the less demanding professional standard of disclosure. States are equally split in their adoption of these two standards. See Laurent B. Frantz, Annotation, Modern Status of Views as to General Measure of Duty to Inform Patient of Risks of Proposed Treatment, 88 A.L.R. 3d 1008 (1978); William M. McNichols, Informed Consent Liability in a "Material Information" Jurisdiction: What does the Future Portend?, 48 OKLA. L. REV. 711, 716 (1995).

41. Hall, Economic Informed Consent, supra note 27; Krause, supra note 33.

42. See Krause, supra note 33, at 262; Devon McGraw, Note, Financial Incentives to Limit Services: Should Physicians be Required to Disclose these to Patients?, 83 GEO. L. J. 1821-47 (1995); E. Haavi Morreim, Diverse and Perverse Incentives of Managed Care: Bringing Patients into Alignment, 1 WID. L. SYMP. J. 89, 120 (1996); Grant H. Morris, Dissing Disclosure: Just What the Doctor Ordered, 44 ARIZ. L. REV. 313 (2002); Susan Wolf, supra note 33, at 1631-81. 
descriptions of the nature and content of payment methods, but also warnings about the possible harms that might occur, and measures that patients can take to protect themselves. ${ }^{43}$ Moreover, to achieve full informed consent, patients would need to be warned about the contrasting harms of fee-for-service payment (which are much better documented) ${ }^{44}$ and informed about the healthpromoting advantages of cost-containment incentives.

There is good reason to question a physician's ability to practice medicine under such unrealistic circumstances. ${ }^{45}$ As the California Supreme Court observed in Arato v. Avedon,

[t]he [clinical contexts] in which physicians and patients interact and exchange information... are so multifarious, the information needs and degree of dependency of individual patients so various, and the professional relationship itself such an intimate and irreducibly judgment-laden one, that we believe it is unwise to require as a matter of law that a particular species of information be disclosed. ${ }^{46}$

43. See generally Comment, Informed Consent: From Disclosure to Patient Participation in Medical Decisionmaking, 76 Nw. U. L. REV. 172, 192-95 (1981) (advocating an exhaustive three-page, fourteenpoint list of guidelines that require physicians to describe the recommended procedure in detail; why the patient's condition might necessitate it; all material risks; the factors used to determine which risks are material; the potential benefits of the procedure; the efficacy of the treatment in achieving those benefits; the risks and benefits of alternative treatments; and why the physician thinks one course is preferable to others. Other suggestions include that the doctor should make special efforts to encourage patient inquiries or have information repeated; he should frequently ask whether the patient understands; and he should inform the patient of his rights to disagree, to choose any alternative, and to change his mind at any time); see also Marc A. Rodwin, Physicians' Conflicts of Interest: The Limitations of Disclosure, 321 NEW ENG. J. MED. 1405, 1405-06 (1989) (claiming that effective disclosures of incentives must have warnings about possible harms); Maxwell J. Mehlman, Fiduciary Contracting: Limitations on Bargaining Between Patients and Health Care Providers, 51 U. PITT. L. REV. 365, 377 (1990).

For instance, the following example, taken from S.D. Goold and H. Brody, would not appear to meet the most demanding versions of informed consent law:

A physician, talking with a patient with typical migraines, might say, "Your headaches are typical for migraines. In about one of 1,000 cases these types of headaches are due to other abnormalities, which we could find on a CT scan or MRI of the head. There is also a good chance (about one out of three) that an 'abnormality' on a scan would not really be there, and this could cause worry and possibly unnecessary further tests. I don't generally recommend scans for migraines because of this risk of error and because they are expensive.

Rationing Decisions in Managed Care Settings: An Ethical Analysis, in HeAlth CARE CRISIS? THE SEARCH FOR ANSWERS 141 (R.I. Misbin et al. eds., 1995).

In comparison, a California court upheld a large plaintiff's verdict for failing to urge a patient forcefully enough to obtain a biopsy on a tiny mole, holding that it was not sufficient for the doctor, a general practitioner, to "strongly recommend [seeing] a specialist" and to warn him that "all pigmented skin lesions are suspicious in nature" until removed and studied microscopically. The court reasoned that the doctor should have specifically mentioned the risk of cancer and its consequences. Moore v. Preventive Medicine Medical Group, 223 Cal. Rptr. 859, 861, 863-64 (Cal. Ct. App. 1986).

44. See generally CHARLES B. INLANDER ET AL., MEDiCine ON TRIAL (1988); Institute OF Medicine of THE NATIONAL ACADEMy SCIENCES, To ERR IS Human: Building A SAFER HeAlth SySTEM (1999); Jason Lazarou et al., Incidence of Adverse Drug Reactions in Hospitalized Patients, 279 JAMA 1200-1205 (1998); Lucian Leape, Unnecessary Surgery, 13 ANN. REV. PUB. HEALTH 363 (1992); Barbara Starfield, Is U.S. Health Really the Best in the World?, 284 JAMA 483 (2000).

45. Hall, Medical Spending Decisions, supra note 10, at 204-09; Sage, Regulating Through Information, supra note 6, at 1763-64.

46. 858 P.2d 598, 606 (Cal. 1993). 
The President's Commission for the Study of Ethical Problems in Medicine noted in its study of informed consent that

further evolution of legal standards toward a firmer protection of individual self-determination in medical decisions must be tempered by a recognition of the law's limits as an instrument of social control.... [T] he Commission is concerned that efforts to draw the law further into regulating the subtler aspects of relations between patients and health care professionals may prove ineffective, burdensome and ultimately counterproductive. ${ }^{47}$

Using liability law to mandate incentive disclosure has the advantage that health plans and providers take liability threats very seriously and so are likely to respond. However, their reactions may be excessive, or may not effectively convey the essential information. Liability law fails to send a clear and consistent message about the nature, timing, source, or extent of required disclosures. This lack of clarity arises both from the variety of liability theories that might be used, and from the uncertainty and inconsistency in how different theories will be resolved, considering that the sufficiency of disclosure is not evaluated until long after it is made, and in circumstances where jurors are likely to be influenced by hindsight bias. ${ }^{48}$ These factors tend to produce confusing, inconsistent, and excessively legalistic responses. For instance, the longer disclosure examples discussed below written by health plan lawyers ${ }^{49}$ are at a college reading level, and one of the more detailed examples is so complex that even a panel of experts had difficulty following it.

Also, liability risks tend to discourage plans from explaining the justifications for and potential effects of physician incentives. As illustrated below, ${ }^{50}$ plans tend to stick to factual descriptions of incentives rather than explaining the potential benefits or drawbacks of incentives, for fear that these explanations might be used against them when a bad treatment outcome occurs. Some health plan lawyers fear that warnings could appear to be admissions of responsibility or that reassurances could be used to claim that the plan has assumed heightened duties or to claim false advertising or broken promises.

Sensing the drawbacks of liability law, courts so far have been reluctant to recognize theories of liability based on nondisclosure of HMO physician incentives. Courts are split on the fiduciary duty theory, with several specifically declining to recognize a claim for breach of fiduciary duty distinct from a medi-

47. PRESIDENT'S COMMISSION FOR THE STUdy OF ETHICAL PROBlEMS IN MEDICINE AND Biomedical and Behavioral Research, MaKing Health CaRe Decisions: The EThical AND LEGAL IMPLICATIONS OF INFORMED CONSENT IN THE PATIENT-PRACTITIONER RELATIONSHIP 30, 204, 252 (1982).

48. See generally Philip G. Peters, Hindsight Bias and Tort Liability: Avoiding Premature Conclusions, 31 ARIZ. ST. L.J. 1277 (1999) (noting the distortion of hindsight judgments by hindsight and outcome bias); Jeffrey Rachlinski, A Positive Psychological Theory of Judging in Hindsight, 65 U. CHI. L. REV. 571 (1998) (exploring the effect of hindsight bias on the legal system).

49. See infra text accompanying notes 87-89.

50. See infra text accompanying notes $85-91$. 
cal malpractice claim. ${ }^{51}$ In the class action suits, the fraud theory was rejected in one case for failure to allege injury, ${ }^{52}$ and in another decision, the court ruled that the fraud claims had not been pleaded with sufficient specificity. ${ }^{53}$ In malpractice cases, state courts have been reluctant to allow evidence of physician incentives for fear that this marginally relevant but potentially inflammatory information will unduly influence jurors. ${ }^{54}$

Although the issue of informed consent liability has not yet been presented in litigation, a number of courts have rejected similar allegations that informed consent was invalidated by a physician's failure to disclose personal characteristics such as substance abuse or lack of experience, which might lessen a procedure's chance of success or increase the odds of a harmful side effect. ${ }^{55}$ The courts seem to be concerned that opening up informed consent law to such wide-ranging personal inquiries would "raise an impracticable, if not impossible, impediment to the efficient rendering of professional services, ${ }^{, 56}$ and would lead to endless and unpredictable demands for "every fact which might conceivably affect performance in the surgical suite." $" 57$

The case for disclosing financial incentives would appear to be even weaker than for the risk factors in these cases. Studies to date show no clear evidence of harm from commonly used financial incentives. ${ }^{58}$ In general, physicians respond to incentives appropriately by following an ethic of impartiality. This does not mean that physicians are oblivious to financial influence. Instead, phy-

51. Ehlmann v. Kaiser Found. Health Plan, 198 F.3d 552, 558 (5th Cir. 2000) (rejecting fiduciary claim under ERISA); Neade v. Portes, 739 N.E.2d 496, 506 (Ill. 2000) (rejecting fiduciary claim under state law).

52. Maio v. Aetna, 221 F.3d 472, 501 (3d Cir. 2000).

53. In re Managed Care Litig., No. 00-1334-MD-MORENO, 2001 U.S. Dist. LEXIS 14501, at*3.

54. Pulvers v. Kaiser Found. Health Plan, 160 Cal. Rptr. 392, 394 (Cal. Ct. App. 1979); Shea v. Esensten, 622 N.W.2d 130, 138 (Minn. Ct. App. 2001); Madsen v. Park Nicollet Med. Ctr., 419 N.W.2d 511, 515 (Minn. Ct. App. 1988), rev'd on other grounds, 431 N.W.2d 855 (Minn. 1988); McClellan v. HMO of Pa., 604 A.2d 1053 (Pa. Super. 1992). But see Neade, 739 N.E.2d 496 at 507 (ruling that evidence of economic motivation is admissible in a medical malpractice case). See generally Paul R. Sugarman \& Valerie A. Yarasbus, Admissibility of Managed Care Financial Incentives in Medical Malpractice Cases, 34 TORT \& INS. L.J. 735 (1999) (exploring conflict generated by market-driven health care).

55. See, e.g., Albany Urology Clinic, P.C. v. Cleveland, 528 S.E.2d 777, 782 (Ga. 2000) (holding that failure to disclose cocaine use does not vitiate patient's consent); Duttry v. Patterson, 771 A.2d 1255, 1259 (Pa. 2001) (holding that no duty exists to disclose lack of experience with a particular surgical procedure); Kaskie v. Wright, 589 A.2d 213, 217 (Pa. Super. 1990) (finding no duty for a surgeon to disclose his alcoholism and lack of license in state where the procedure was performed); Whiteside v. Lukson, 947 P.2d 1263, 1265 (Wash. Ct. App. 1997) (holding that no duty exists to disclose lack of experience with a particular surgical procedure).

56. Albany Urology Clinic, 528 S.E.2d at 782 n.19.

57. Kaskie, 589 A.2d at 214 (Pa. Super. 1990).

58. D.M. Berwick, Payment by Capitation and the Quality of Care, 335 NEW ENG. J. MED. 1227 (1996); R.A. Dudley et al., The Impact of Financial Incentives on Quality of Health Care, 76 MILBANK Q. 649 (1998); Fred J. Hellinger, The Impact of Financial Incentives on Physician Behavior in Managed Care Plans: A Review of the Evidence, 53 MED. CARE RES. \& REV. 294 (1996); Nicole Lurie et al., The Effects of Capitation on Health and Functional Status of the Medicaid Elderly: A Randomized Trial, 120 ANNALS INTERN. MED. 506 (1994); MARTIN GAYNOR, ET AL., INCENTIVES IN HMOs, (Nat'l Bureau of Econ. Research, Working Paper No. 8522, 2001). 
sicians, on average, alter their practice styles consistently for all of their patients rather than differentiating among patients based on the particular payment method under each type of insurance. ${ }^{59}$

On balance, if incentive disclosures are accurate and reasonably understandable, even brief disclosures should suffice to counter most liability theories based simply on the failure to disclose, such as claims of fraud and breach of fiduciary duty. More extensive disclosures that contain warnings and achieve true understanding might be necessary under extensions of the most aggressive versions of informed consent liability, or if a malpractice defendant is attempting to claim that a patient consented to a lower standard of care or waived claims based in negligence. These are much more potent legal effects, however, than simply authorizing or acknowledging a particular payment method or a potential conflict of interest, which is all that normally is at issue in a legal dispute over incentive disclosure.

\section{B. Regulatory Requirements}

Disclosure of HMO physician incentives is also required by several sources of regulatory law. The first such requirement was imposed in 1996 on HMOs participating in Medicare and Medicaid, as part of the extensive regulation of physician incentives under these government programs. ${ }^{60}$ These regulations require disclosure of incentives only if an HMO member specifically requests this information. Of greater impact are requirements for routine disclosure adopted as part of the movement over the past few years to strengthen patient rights and patient protections in managed care plans. ${ }^{61}$ Physician incentive disclosures are required by the "patients' bill of rights" or similar rules enacted in approximately twenty states, and imposed by executive order on health plans for federal employees. ${ }^{6}$ The most universal regulation is one that limits the extent to which health plans may include so-called "gag clauses" in their contracts with physicians. These clauses are meant to bar physicians from revealing trade secrets or disparaging the plan, but they also could have the effect of preventing physicians from telling patients essential information about their treatment options or how their plan functions. Virtually all states prohibit gag clauses that have the latter effects. ${ }^{63}$

59. Mark A. Hall et al., Capitation Payment, Length of Visit, and Preventative Services: Evidence From a National Sample of Outpatient Physicians, 8 AM. J. MANAGED CARE 332 (2002); Laurence Baker, Association of Managed Care Market Share and Health Expenditures for Fee-for-Service Medicare Patients, 281 JAMA 432, 436 (1999); Sherry Glied \& Joshua Zivin, How Do Doctors Behave When Some (But Not All) of Their Patients are in Managed Care?, 21 J. HEALTH ECON. 337 (2002).

60. 42 C.F.R. $\$ \S 417.479(\mathrm{~h})(3), 434.70$.

61. U.S. GOVERnMENT ACCOUNTING OFFICE, CONSUMER HeAlth CARE Information: MANY QUALITY COMMISSION Disclosure RECOMMENDATIONS ARE Not CURRENT PRACTICE, GAO/HEHS 98-137 (1998).

62. Tracy E. Miller \& William M. Sage, Disclosing Physician Financial Incentives, 281 JAMA 1424, 1424 (1999).

63. Krause, supra note 33, at 376-78; Sloan \& Hall, supra note 16. 
In about half the states with affirmative disclosure requirements, the law requires only very brief statements of how physicians are paid. Examples in use range from the Rhode Island statute ${ }^{64}$ which requires only a bare statement of whether the health plan "utilizes capitated arrangements with its participating providers or contains other similar risk sharing arrangements," to New Jersey regulations, ${ }^{65}$ which require only a brief definition: "your provider may be paid a set fee each month for each member whether or not the member actually receives services (capitation)," and "these payment methods may include financial incentive agreements to pay some providers more ('bonuses') or less ('withholds') based on many factors: member satisfaction, quality of care, and control of costs and use of services among them." This information is included in materials sent to potential members prior to their choosing a plan. Many states require instead, or in addition, that plans give lengthier descriptions of physician incentives and that this information be included in the certificate of coverage or other materials sent to members following enrollment. ${ }^{66}$

So far, these regulations have produced little or no controversy. Compliance is widespread, as noted below, ${ }^{67}$ and no enforcement actions have been reported. ${ }^{68}$ Most of the health plans interviewed in the study described below ${ }^{69}$ said that the primary impetus to begin incentive disclosure was the requirement under Medicare that HMOs disclose physician payment methods if this information is requested by members. Although members rarely make such a request, Medicare HMOs must submit their disclosure language for regulatory approval, so all were required to development disclosure statements. Having done so, many plans decided to include this disclosure routinely in their certificates of coverage sent to members. Other plans do so in response to state regulatory requirements, and a few respond to anticipated threats of liability.

Thus, it appears that health plans have been willing all along to disclose basic information about financial incentives but were not willing to take the initiative in being the first to do so. Consistent with the collective action and the "lemons" explanations noted above ${ }^{70}$ an external mandate was required to ini-

64. R.I. GEN. LAWS § 23-17.13-3(c)(9) (2001).

65. N.J. ADMIN. CODE tit. 38, § 13.4 (2001).

66. See, e.g., Minn. STAT § 62J.72 (2001).

67. See infra text accompanying notes 72-77.

68. This quiescence is in contrast to the nature and existence of the incentives themselves. In Texas, several lawsuits have been brought under a statute that prohibits financial incentives to withhold medically necessary care. TEX. INS. CODE ANN. art. 20A.14(1) (2001). The Texas Department of Insurance entered into a consent order with the Harris Health Plan (an HMO run by Harris Methodist Hospital in Dallas), calling for it to cease using certain aggressive financial incentive plans, to pay a $\$ 100,000$ fine, and to refund to physicians several million dollars of withheld payments. Press Release, Texas Department of Insurance, Harris HMO Drops Incentives, Agrees to Pay 3.4 Million (Aug. 19, 1998), available at http://www.tdi.state.tx.us/commish/nr08198.html. Another suit, brought by the Texas Attorney General against Aetna, also resulted in a settlement calling for a wide range of restrictions and changes in various managed care practices and policies. A press release and copy of the agreement can be found at http://www.aetna.com/news/2000/pr_20000411.htm.

69. See infra text accompanying notes 74-75.

70. See supra text at note 22 . 
tiate disclosure, but plans saw no compelling reason either to resist vigorously having this requirement imposed or to resist compliance once it was imposed. It appears that liability threats are not needed to induce incentive disclosure by health plans. Moreover, a regulatory approach is much better suited to giving clear notice of what is legally required and to specifying the optimal source, timing, and content of disclosure.

IV

\section{DISCLOSURE IN PRACTICE}

As recently as early 1998, it was reported that virtually no health plans were disclosing physician incentives. ${ }^{71}$ This state of affairs has been changing rapidly. As a consequence of the legal developments just described, most national health plans now routinely disclose in general terms how they pay their physicians. Thus, discussion has quickly shifted from whether disclosure should occur to how, when, and what should be disclosed, and by whom. This section reports on two sources of empirical evidence about incentive disclosures-one qualitative $^{72}$ and one quantitative. ${ }^{73}$ In the qualitative study, conducted primarily in mid-1999, twenty key informants were interviewed who had extensive experience with incentive disclosure issues ${ }^{74}$ and sixty-four examples of existing disclosure statements were collected from fourteen private insurers and five government authorities. ${ }^{75}$ In the quantitative study, the actual effects on knowledge of incentives and on trust in physicians and health plans were rigorously assessed using a randomized controlled experimental design $^{76}$ in which the incentive disclosures quoted in this note were given both by mail and by phone. $^{77}$ Evidence from these and other studies reveals how health plans have

71. U.S. Government Accounting Office, supra note 61, at 98; Hall, Economic Informed Consent, supra note 27 , at 517 .

72. See Mark A. Hall, Kristin E. Kidd, \& Elizabeth Dugan, Disclosure of Physician Incentives: Do Practices Satisfy Purposes?, HEALTH AFF., July/Aug. 2000, at 156.

73. See Mark A. Hall et al., How Disclosing HMO Physician Incentives Affects Trust, HEALTH AFF., Mar./Apr. 2002, at 197.

74. The informants consisted of eight academics or public policy analysts, five regulators, four health plan representatives, two patient and consumer advocates, and one private lawyer. Mark A. Hall et al., Interviews with Twenty Key Informants and Supporting Materials (1999)(unpublished raw data that was summarized in Hall et al., supra note 73, on file with authors) [hereinafter Unpublished Interviews].

75. This sample represents disclosures used for Medicare enrollees and federal employees and disclosures used by HMOs representing over one third of the private market, including four of the nation's five largest HMOs. Id.

76. Specifically, we recruited 1,918 members of an $\mathrm{HMO}$ and randomly assigned them to disclosure and control groups. Knowledge of incentives and trust in the health plan, as well as in one's primary care physician, were assessed at baseline and two months later. In between the two assessments, the experimental group received both a mailing and a phone call disclosing the health plan's capitation and withhold-payment methods, using the language quoted infra in note 77 . In the phone call, the disclosure was read aloud and a set of questions was administered to assess comprehension and to reinforce learning; the disclosure was repeated when comprehension was lacking. These extra efforts were taken because the primary purpose was to assess the impact of learning this information rather than to test the efficacy of actual disclosure methods in use. See Id.

77. Half the subjects received the following disclosure, focusing on capitation payment: 
responded to legal requirements for incentive disclosure, and what impact these disclosures are likely to have on those who receive them.

\section{A. Types of Incentive Disclosure ${ }^{78}$}

1. Source and Timing of Disclosure. Overwhelmingly, disclosure is made by health plans, not by physicians or other providers. Legal mandates have focused on health plans because incentives originate from and are shaped by them, and because the point of enrollment is the most convenient time for making disclosures. Additionally, both physicians and patients are uncomfortable with direct discussions of financial incentives or other aspects of payment, especially during treatment. ${ }^{79}$ Physicians fear this will undermine trust, and patients believe it would be inappropriate or potentially offensive to raise or pursue such matters with their physicians. Therefore, disclosure and discussion by physicians remains extremely rare..$^{80}$

Disclosure by health plans can occur either prior to enrollment, while people are evaluating their options among health plans, or shortly following enrollment, as part of the certificate of coverage and other legal documents they receive from their plan. Pre-enrollment disclosures are meant to facilitate more informed choices among insurance options. Although this is a worthwhile goal, almost none of our key informants, including the regulators and patient advo-

We pay your primary care physician a fixed amount each month to take care of your medical needs. If your medical care costs less than this amount, your doctors can keep the remaining money. If your medical care costs more than this amount, your doctors may lose money. This may encourage your doctor to lower the costs of treatment. Your doctor can do this by:

- keeping you healthy and treating your illness before it gets worse

- not ordering treatment your doctor thinks you do not need, or

- using less expensive treatment that your doctor thinks works just as well or better than more expensive treatment.

We also pay your primary care physician a bonus each year based in part on how well he or she holds down costs, provides preventive care, and satisfies patients' expectations.

The other half received a different disclosure, focusing on a withhold pool:

We pay your primary care physician for each service you receive. This may encourage your doctor to perform more services.

To encourage your doctor to hold down costs and to deliver good service and quality care, your primary care physician can also earn a bonus up to an average of 25 percent. This bonus is based in part on how well your doctor:

- holds down costs

- provides preventive care

- satisfies patients' expectations

If a doctor, or other doctors in the same office, do poorly on one or more of these measures, they can lose some or all of this bonus.

Id.

78. This section is adapted from Hall, Kidd, \& Dugan, supra note 72.

79. See Wendy Levinson et al., Resolving Disagreements in the Patient-Physician Relationship: Tools for Improving Communication in Managed Care, 282 JAMA 1477, 1477-83 (1999); Tracy E. Miller \& Carol R. Horowitz, Disclosing Doctors' Incentives: Will Consumers Understand and Value the Information?, HEALTH AFF., July/Aug. 2000, at 149.

80. Stephen D. Pearson \& T. Hyams, Talking about Money: How Primary Care Physicians Respond to a Patient's Question about Financial Incentives, 17 J. GEN. INTERN. MED. 75 (2002). 
cates, thought this to be an achievable goal with respect to physician incentives. Two prominent patient advocates in the study said that, although they once thought it was crucial for people to understand prior to joining a plan how its physician incentives operate, they now think this is not very feasible. In fact, they think that this is not information that consumers are likely to consider in making their decisions. Industry representatives and regulators in our study agreed. Despite the fact that Colorado was a leader in implementing a range of preenrollment disclosure requirements, its regulators rescinded the physician incentive aspect of their mandated disclosures soon after they were implemented. $^{81}$

When pre-enrollment disclosures occur, they are extremely limited. As noted above, ${ }^{82}$ they provide only a bare statement and the briefest of definitions concerning the use of salary, fee-for-service, capitation, or risk-sharing arrangements. Several informants explained that more elaborate explanations would overwhelm people with information at a point at which it is not highly relevant; thus, people are unlikely to consider it. Also, prior to enrollment, it is often not possible to identify which physician or practice group a member will have, so it is necessary to mention the full range of possible payment incentives that might be used in the network rather than targeting the ones that will be used for a member's own physicians. ${ }^{83}$ Finally, assuming it would be possible to convey information about financial incentives clearly and succinctly, the evidence discussed below indicates that few people would view this as relevant in actual decisions about selecting a health plan. ${ }^{84}$

Therefore, most of the effort in incentive disclosure is focused on disclosures made following enrollment. Physician payment is one of many plan attributes that are described in legal documents sent to subscribers shortly after they first join the plan. This provides ample opportunity to make disclosures as extensive and detailed as anyone might desire. The examples collected from five plans and the Department of Health and Human Services ranged from approximately three to eight hundred words, with an average of over five hundred.

2. Content of Disclosures. The content of disclosures can be categorized according to the three purposes identified at the outset of this paper. An unadorned description suffices to meet the "lemons" justification, which observes the absence of information needed for the operation of efficient markets. A description that discusses the possible effects of incentives, both negative and beneficial, is addressed more to the agency theory justification, which seeks to warn patients about potential conflicts of interest. A broader-

81. Hall, Kidd, \& Dugan, supra note 72, at 157-58.

82. See supra text accompanying notes 64-65.

83. For instance, the Colorado regulation, subsequently repealed, required plans to state the percentage of physicians paid by each method. COLO. REG. 4-2-20 (1998). Regulators there believe this summary level of information is not meaningful for most consumers. Hall, Kidd, \& Dugan, supra note 72 , at 158 .

84. See infra text accompanying note 108 . 
ranging explanation is needed to advance educational goals that place incentives in the context of health policy and other cost-containment mechanisms. Various examples of each of these three types of disclosures can be found in current use.

a. Bare notice and elaborate description of just the facts. Purely descriptive disclosures range from bare statements and simple definitions to lengthy, elaborate descriptions. What unifies all of these disclosures, despite their differing lengths, is that little or no mention is made of the reasons for different financial incentives and their potential impact on physician behavior. All that is discussed is the structure and content of incentives. Nevertheless, because of the complexity of these incentives, the disclosures generate ample material for descriptions, which might include each of the following:

(1) Base pay: fee-for-service, capitation, salary, per episode

(2) Additional incentives: bonuses, withholds, risk pools

(3) Limits on incentives: stop-loss, risk adjustment, no gag clauses, other safeguards

(4) Level of incentives: plan vs. group vs. individual ${ }^{85}$

The most common form of base pay that raises incentive issues is capitation. Various definitions in use all convey the basic idea of a fixed amount per member. Some descriptions include the scope of services covered by capitation or emphasize that payment does not vary by the amount of care. For example,

Physicians are paid a fixed amount of money each month to provide specific services to the members they see. This capitation payment may be divided into separate amounts for the services they provide directly to their patients, services provided by referral physicians, and for hospital and other types of services.

"Capitated" payment means the network provider's annual reimbursement is based on a fixed monthly amount for each member who accesses services through the provider.... If the annual capitation amount is less than the cost of providing or arranging for a member's health services, the provider generally bears all or some part of the shortfall. If the annual capitation amount is more than the provider's costs, the provider generally receives all or some part of the excess. ${ }^{86}$

Bonus, withhold, and risk pool incentives can be used in various combinations and with different base pay arrangements. Some disclosure statements devote several long paragraphs to explaining these different structures and to distinguishing among them. None, however, gives the exact percentages or dollar amounts at stake. A few give a range, maximum, or typical percentage, but our informants did not think it feasible to give greater detail because the precise amounts change over time and, within many networks, vary considerably. Existing disclosures do not precisely define the basis for paying these amounts but instead indicate only whether payment is based solely on cost and utilization, or is also based on quality and satisfaction measures. Finally, none tells the size of the pool over which these incentives and measures are spread,

85. Hall, Kidd, \& Dugan, supra note 72 , at 161.

86. Id. 
and only a few indicate briefly how the payment is distributed within the pool. Here is one of the more detailed examples:

For some network providers paid on a fee-for-service basis, ... [the Plan] holds back some of the fee-for-service payment amount. The withheld amount generally will not exceed [fifteen percent] ([five percent] for some network hospital[s]) of the fee schedule amount. These providers can earn the withheld amount based on certain factors. These factors can include the financial circumstances of [the Plan], and other aggregate and individual measures such as quality, efficient, cost-effectiveness and member satisfaction. These factors apply in various ways to different types of providers. [The Plan's] Board of Directors may review these factors and decide what amount, if any, of the withheld amount to pay the providers. Based on individual measures, the percentage of the withheld amount paid if any, can vary among providers. ${ }^{87}$

Disclosures also mention arrangements, such as capping the maximum loss, that limit the degree of financial risk. One plan also notes that it is nonprofit, but does not elaborate on the significance of this corporate form. Another plan describes risk adjustment factors used to avoid unfairly penalizing physicians with sicker-than-average patients. ${ }^{88}$

One other notable innovation is a standardized disclosure required in Maryland, which uses a familiar clinical scenario involving pregnancy care and birth by Caesarean section to illustrate different types of incentives:

Fee-for-Service:

The amount of payment Dr. Jones receives will depend upon the number, types, and complexity of services, and the time she spends providing services to Mrs. Smith. Because Caesarean deliveries are more complicated than vaginal deliveries, Dr. Jones is paid more to deliver Mrs. Smith's baby than she would be paid for a vaginal delivery.

Salary:

During the months of providing prenatal care to Mrs. Smith, Dr. Jones' salary is unchanged. Although Mrs. Smith's baby is delivered by Caesarean section, a more complicated procedure than a vaginal delivery, the method of payment will not have any effect upon Dr. Jones' salary.

Capitation:

Dr. Jones' monthly payment does not change as a result of her providing ongoing care to Mrs. Smith. The capitation amount paid to Dr. Jones is the same whether or not Mrs. Smith requires obstetric services.

Case rate:

All office visits for prenatal and postnatal care, as well as the delivery, and hospitalrelated charges are covered by one fee. Dr. Jones, the hospital, and other providers (such as an anesthesiologist) will divide payment from the insurer or HMO for the care provided to Mrs. Smith.

Finally, existing disclosure statements usually address only the incentives created by the health plan's payment to physician groups, not by how groups pay each physician. When incentives are paid to groups of physicians, the pay-

87. $I d$.

88. "Adjustments to compensation ... are made based upon the degree of patients' illnesses in each practice and are compared to other PCPs with similar practices in their areas." Data summarized in Hall, Kidd, \& Dugan, supra note 72, on file with authors [hereinafter Unpublished Data].

89. Id. 
ment of individuals within the group might be entirely different than the payment to the group. For instance, a capitated group might pay member physicians a salary or some form of fee-for-service. ${ }^{90}$ Only a few disclosures acknowledge this distinction. They instruct members to speak to their physicians for more information on a physician's specific incentives. Group- and staff-model HMOs are in a position to disclose incentives at both levels, but network or Independent Practice Associations ("IPA") model HMOs are not. HMOs usually are not in a position to disclose payment information at a physician-specific level within a group, because not only do they have no say over how independent physician groups pay their members, but they usually are not even entitled to know this.

The few plans that do disclose physician-level payment structures summarize all the different payment arrangements used for various groups in the network rather than focus on the arrangements that are specific to each member's physician or group. Thus, a single disclosure statement is written for all situations, and members are told they can contact the plan for more specific information about a particular provider. As noted previously, members rarely do so. ${ }^{91}$

b. Warnings and fully informed consent. Although many of the disclosure statements we reviewed are quite lengthy, almost none of them met the most extended informed consent model because there is virtually no mention of the potential negative impact that incentive arrangements might have on physician behavior. A few disclosures briefly state or imply that incentives might induce physicians to reduce services, ${ }^{92}$ but only one says that some reduced services might be beneficial, and it quickly disavows using bad incentives:

An improperly used incentive may encourage a physician to provide a patient with a less effective treatment because it is less expensive. [This HMO] will not improperly use incentives to compensate physicians ....

Rather than issue dire warnings, health plans more frequently paint incentives in a positive light. ${ }^{94}$ They disavow any intent to discourage necessary care, they observe that incentives reward improved health and early aggressive disease management, and they point out that incentives are often paid under a formula that includes rewards for improving satisfaction, retaining patients, and meeting preventative service goals. ${ }^{95}$ For example:

Plan compensation arrangements are designed to encourage the provision of the most appropriate care for each patient and to discourage the provision of unnecessary and potentially detrimental services. The Plan incorporates specific "quality factors"

90. James C. Robinson, Blended Payment Methods in Physician Organizations Under Managed Care, 282 JAMA 1258, 1258 (1999).

91. See supra text accompanying note 68 .

92. For example, one disclosure states, "your physician or provider has a financial incentive to reduce and control the costs of providing medical care." Unpublished Data, Hall, Kidd, \& Dugan, supra note 88.

93. $I d$.

94. $I d$.

95. Id. 
into the compensation process.... There are no plan compensation incentives or penalties that are intended to encourage providers to withhold services or to minimize or avoid referrals to specialists.

Appropriate financial incentives are intended to:

- reduce waste in the application of medical resources

- eliminate inefficiencies which may lead to artificial inflation of health care costs

- encourage physicians and health care providers to practice preventive medicine and focus on improving the long-term health of patients

- direct attention to patient satisfaction

- improve the efficient delivery of quality health care services without compromising the quality and integrity of the physician-patient relationship.

Only appropriate financial incentives will be used to compensate physicians.... There are no plan compensation incentives or penalties that are intended to encourage providers to withhold services or to minimize or avoid referrals to specialists.

Provider compensation is adjusted based on results in various areas, including: appropriate diagnostic testing, specialty and hospital utilization; member satisfaction survey results; thoroughness of medical chart documentation; clinical care measures for diabetes, asthma, and other conditions; number of scheduled office hours; range of office procedures offered; around-the-clock coverage; and participation in continuing education programs.

c. Educational objectives. Only one plan was identified whose primary approach to disclosure was educational. Its medical director wrote a personal, two-page letter to all members explaining how physician incentives operate within the context of inflationary incentives and the need for cost containment, as well as stressing the positive features of these incentives. ${ }^{97}$ One other health plan included a brief reference to the cost-containment goals of physician incentives:

One of the purposes of managed care is to manage and control the cost of health care. Financial incentives in compensation arrangements with physicians and health care providers are one method by which [the HMO] attempts to manage and control the cost of health care.

About half of the health plans interviewed said that disclosure done primarily for legal reasons also has a partial educational objective of countering widespread misunderstanding or suspicion of how financial incentives operate in managed care. Also, some plans would like to use disclosure to their advantage by touting the merits of their incentives over those of competitors.

Surprisingly, most disclosures contain no reference to the larger context that gives rise to physician incentives, as proposed by Morreim. ${ }^{99}$ Health plan representatives said they have not done so in part because of their concern that a more explanatory justification of incentives might not meet regulatory requirements. Despite these difficulties and concerns, most participants felt that disclosure of incentives should be used as an opportunity to educate members

96. $I d$.

97. See infra Appendix B.

98. Unpublished Data, Hall, Kidd, \& Dugan, supra note 88.

99. See infra Appendix B. 
about the purposes and benefits of cost controls and managed care techniques. Plan representatives believe, however, that they need to fashion disclosures primarily to satisfy the legal objectives of regulatory compliance and risk management. Therefore, the dominant view is that educational objectives are in tension with disclosures done for legal compliance.

d. The impact of incentive disclosure. The effects of incentive disclosures have been assessed both in terms of how well they convey information and whether they have any impact on attitudes or behavior. Studies of disclosure by other types of insurers have concluded that insurance disclosures rarely have any impact because few people bother to read them, and, when they do, they do not find the information especially meaningful. ${ }^{100}$ This also characterizes the informed views of the subjects in the qualitative study above. When asked what impact incentive disclosures have had, the four plan representatives said they have been a "big yawn," "useless," and have not caused "even a ripple" of a reaction. ${ }^{101}$ One large plan which, like others, invites members to call if they have questions or want additional information, received only two inquiries in the first two years. Similarly, under the Medicare rules, regulators and plans reported that beneficiaries who are told that they have the right to request information about physician incentives rarely or never do so.

The difficulty in conveying understanding of incentives is demonstrated by the limited success of the extensive efforts at disclosure that were undertaken in the quantitative study. A disclosure statement was produced that is much simpler (although still detailed) compared to existing statements. ${ }^{102}$ Its mailing to members was followed by a phone call in which the statement was read aloud and repeated if subjects failed to correctly answer simple comprehension questions immediately after the first reading. ${ }^{103}$ Despite a fifty-percent increase in knowledge of incentives, ${ }^{104}$ one month following the disclosure the majority of

100. Roger Formisano, The NAIC Model Life Insurance Solicitation Regulation: Measuring the Consumer Impact in New Jersey, 48 J. RISK \& INS. 59, 79 (1981); J.E. Russo \& F. Leclerc, Characteristics of Successful Product Information Programs, 47 J. SOC. IsSUES 73, 74 (1991); LARRY Kirsch, Do PRODUCt Disclosures INFORM AND SAFEguARD INSURANCE POLICYHOLDERS? (2001).

101. Hall, Kidd, \& Dugan, supra note 72, at 159-60.

102. Unpublished Data, Hall, Kidd, \& Dugan, supra note 88.

103. The questions varied depending on the exact disclosure given. The following set of questions was used for the first disclosure quoted supra note 77. The correct answer to each is "yes":

1) Does [the $\mathrm{HMO}$ ] pay your doctor a fixed amount each month, no matter how many or few services you receive?

Does [the HMOs'] payment method:

2) reward your doctor for keeping you healthy?

3) reward your doctor for providing less care or fewer services?

4) reward your doctor for holding down costs?

104. Specifically, between the baseline (pre-disclosure) survey and the one month follow-up, twice as many intervention subjects correctly answered at least three out of four comprehension questions that asked about the basic structure of each payment method (fixed amount vs. fee-for-service) and about several incentive effects (health promotion, cost savings, fewer/more services). Unpublished Interviews, supra note 74. 
subjects were not able to correctly recall the answers to more than half the comprehension questions, and fourteen percent had no correct responses.

This result is consistent with a focus group study that found that some people have great difficultly grasping the notion that different payment structures might affect physicians' behavior. ${ }^{105}$ We should expect that more realistic disclosure methods than those used in these artificial studies will be even less successful in conveying basic understanding. Communication theory and research establish that the success of information disclosure depends on the amount and complexity of information, the recipient's prior familiarity with the information, and the information's salience. ${ }^{106}$ None of these conditions lends itself to easy comprehension of physician incentives.

When disclosure does succeed in improving understanding of incentives, then what impact can we expect on people's attitudes and behaviors? Critics of physician incentives claim that disclosing them will undermine trust, and therefore that much of the push for disclosure is to discourage plans from using incentives at all. However, disclosing incentives appears to have limited or no impact on patient trust of physicians and health plans, and may actually have a positive effect. In the controlled disclosure experiment, despite a doubling in understanding of these incentives, the experimental group showed no decline in trust in their health plans and only modest increase in trust in their physicians as compared with the control group. ${ }^{107}$

Although these results from a single study shed only limited light on the actual impact of such disclosures ${ }^{108}$ they are consistent with findings from another, more qualitative, study, which also indicates that most people are not greatly troubled to learn that health plans include cost-containment incentives in their physician compensation methods. ${ }^{109}$ Studies of factors that affect the purchase of insurance indicate that price, coverage, structure, and composition of the provider network, quality of care, and satisfaction with service are more

105. Tracy E. Miller \& Carol R. Horowitz, Disclosing Doctor's Incentives: Will Consumers Understand and Value Information?, HEALTH AFF., July/Aug. 2000, at 149.

106. See Judith Hibbard et al., Implications from Decision-Making Research, 75 MILBANK Q. 395, 396 (1997).

107. Hall et al., supra note 73 .

108. This study is limited by the following factors: (1) the study was done in only a single health plan located in a southeastern state; (2) only certain types of incentives were described, which included some positive health-promoting and service-enhancing features that not all health plans include; (3) the effects of disclosure were tested over only a short time; and (4) the evaluated effects were attitudinal only and not behavioral. However, these limitations should not seriously undermine the study's validity for the following reasons: (1) the study population was diverse and its relevant characteristics were similar to national norms; (2) the incentives described were of a significant size (up to twenty-five percent, compared to the ten to fifteen percent that is often used, and the disclosure went further in describing the potentially negative effects than do many other disclosures in current use); (3) if there were effects on attitudes, they would be expected to appear soon or immediately after the disclosure rather than having a lagged effect; and (4) there is no particular reason to expect behavioral effects (such as switching plans or physicians or obtaining second opinions) to appear in the absence of attitudinal effects. For additional discussion, see Hall et al., supra note 73.

109. Miller \& Horowitz, supra note 105. 
important to insurance subscribers than how physicians are paid. ${ }^{110}$ While the choice between indemnity versus managed care is high on this list, operational nuances among managed care plans are not, except to the extent that they impact bottom-line indicators such as price, quality, and satisfaction.

The gist of these initial studies is that patient trust is rooted more in the fundamental aspects of seeking care in the condition of illness, and in patients' past experiences with their providers, than in institutional and economic factors that arguably affect the delivery of care. ${ }^{111}$ Factors that matter in theory, or that matter to experts, do not necessarily affect the actual attitudes and behavior of the vast majority of patients in practice. For most people, the details of how health plans pay physicians appear to fall into this category of secondary informational interest. This does not mean, though, that disclosure is pointless. Surveys show that people are interested in learning about physician incentives. ${ }^{112}$ Even if the information does not change many people's decisions, people still have good reason to want to know. And, even if the information is rarely actually read, the integrity of the relationships among patients, physicians, and health plans requires that this information be made available for those who do want to know it. There is little indication, however, that learning about financial incentives will either alter many people's decisions or change their views of their physician or health plan.

\section{V}

\section{CONCLUSION-A LAYERED APPROACH TO DISCLOSURE}

Despite the widespread consensus that physician incentives under managed care should be disclosed, there is little agreement on the who, what, when, and how of disclosure, nor is there agreement on the primary purpose of disclosure. Three forms of market failure point to three distinct, but overlapping, purposes of disclosure, each of which points toward different forms, sources, and contents of disclosures. This complex matrix is summarized in the following chart.

110. See generally Susan Edgman-Levitan \& P. Cleary, What Information Do Consumers Want and Need?, HeAlth AFF., Winter 1996, at 42; J.H. Hibbard \& J.J. Jewett, What Type of Quality Information Do Consumers Want in a Health Care Report Card?, 53 MED. CARE RES. \& REV. 28 (1996); Stephen Isaacs, Consumers' Information Needs: Results of a National Survey, HEALTH AFF., Winter 1996, at 31; J.S. Lubalin \& L.D. Harris-Kojetin, What do Consumers Want and Need to Know in Making Health Care Choices?, 67 MED. CARE RES. \& REV. 56 (1999); Miller \& Horowitz, supra note 79; Shoshanna Sofaer, Informing and Protecting Consumers under Managed Competition, HEALTH AFF., Winter 1993, at 76; Anne Tumlinson et al., Choosing A Health Plan: What Information Will Consumers Use?, HeALTH AFF., May/June 1997, at 229.

111. Mark A. Hall et al., Trust in Physicians and Medical Institutions: What Is It, Can It Be Measured, and Does It Matter?, 79 MiLbanK Q. 613 (2001).

112. Thomas H. Gallagher et al., Patients' Attitudes Towards Cost Control Bonuses for Managed Care Physicians, HeAlTh AFF., Mar./Apr. 2001, at 186. 
TABLE 1

\begin{tabular}{|l|l|l|l|}
\hline $\begin{array}{l}\text { Market } \\
\text { Failure }\end{array}$ & $\begin{array}{l}\text { Disclosure } \\
\text { Purpose }\end{array}$ & Disclosure Content & Disclosure Source and Timing \\
\hline $\begin{array}{l}\text { "Lemons" } \\
\text { phenomenon }\end{array}$ & $\begin{array}{l}\text { Stimulate } \\
\text { competition }\end{array}$ & $\begin{array}{l}\text { The bare structure of } \\
\text { incentives }\end{array}$ & Any \\
\hline $\begin{array}{l}\text { Imperfect } \\
\text { agency }\end{array}$ & $\begin{array}{l}\text { Warn of } \\
\text { conflict of } \\
\text { interest }\end{array}$ & $\begin{array}{l}\text { Detailed description } \\
\text { of incentives and } \\
\text { possible effects }\end{array}$ & $\begin{array}{l}\text {-Health plans, pre-enrollment } \\
\text {-Physicians, prior to or during } \\
\text { treatment }\end{array}$ \\
\hline Public goods & $\begin{array}{l}\text { Educate the } \\
\text { public }\end{array}$ & $\begin{array}{l}\text { Purposes of } \\
\text { incentives }\end{array}$ & Health plans, after enrollment \\
\hline
\end{tabular}

Clearly, no one theory and method of disclosure can satisfy each of these multiple concerns. However, there need not be one solution to this problem. Professor Susan Wolf insightfully observes that the debate over incentive disclosure has wrongly assumed that there should be a single "magic moment" of disclosure. ${ }^{113}$ Instead, this issue calls for a systemic, multistaged approach in which information about incentives is revealed by different sources, at different times, and in varying levels of detail. Professor Wolf's suggestion is also consistent with cognitive psychology and communication research, which remind us that information is best presented in a manner that fits the decisions and concerns that people face, at the time they face them, recognizing differences among individuals and over time. ${ }^{114}$

Consistent with Professor Wolf's proposal, ${ }^{115}$ it is possible to accomplish this difficult task through a layering approach, one that provides different levels of information at different times, allowing people to learn what they want in response to their varying levels of interest, concern, and ability to absorb the information. ${ }^{116}$ In the present context, layering of information might be accomplished in a number of ways. What follows is merely one suggestion for how to do so.

(1) Prior to enrollment, potential subscribers can be told simply whether plans use physician incentives in any fashion to contain costs, as one aspect of distinguishing managed care generally from traditional fee-forservice indemnity coverage, and potential subscribers can receive additional, more detailed information if they request it. This bare statement might simply say that "this health plan pays physicians in a way that rewards them for lowering the costs of treatment" or "... rewards them for providing more treatment."

113. Wolf, supra note 33, at 1680.

114. Id.

115. Id. However, the details of this proposal differ significantly from hers.

116. See Hibbard et al., supra note 110. 
(2) Following enrollment, managed care members can be given fairly detailed descriptions of the various physician incentive arrangements used in the network, as part of the plan's legal documents and explanation of how it operates. These explanations can, but need not, also discuss the purposes and potential positive and negative effects of these incentives. This additional explanation might help to advance an educational purpose, but the reality is that very few people can be expected to actually read disclosures at this stage. This detailed level of disclosure exists primarily as a contractual formality, to meet basic legal requirements and to provide an opportunity to learn the facts about incentives for those who desire this information.

(3) When a patient signs up with or identifies a specific physician, either the plan or the physician group can inform the patient in writing of the incentive arrangements directed to the particular group and within the group. Some clinics have a brochure that describes the basic organization and structure of the clinic. These disclosures could be expanded to include financial and contractual arrangements with health plans and with referral physicians, or they could go further to discuss the group's basic philosophy of medical practice. Another model, one that is more legalistic, comes from inflationary conflicts of interest under fee-forservice. Some states require physicians with an ownership or investment interest in a medical facility or service to disclose that interest when making a referral to the facility or service. ${ }^{117}$ Lawyers have devised written disclosures for this purpose that might serve as a workable starting point for physicians to disclose managed care incentives.

(4) At any point, a person who wants additional information should be told whom to contact, including his personal physician, and that contact person should be prepared to discuss candidly the general structure, purpose, and potential effects of various physician incentives. With respect to medical treatment decisions, this means that it is up to each individual how to assess the impact incentives might have on a physician's recommendations and whether to raise these issues or to request more information about incentives or treatment options before consenting to particular procedures. If raised even indirectly, physicians should be sensitive and receptive to these inquiries rather than defensive or obtuse. ${ }^{118}$

(5) At each of these stages, fiduciary legal principles do not require a full articulation of all the dimensions and possible effects of payment incentives. All that is required is a description of the basic structure of the

117. Glen A. Reed \& Robert E. DeWitt, Referral Fee Prohibitions, in HEAlth CARE CORPORATE LAW: FINANCING AND LiABILITY 7-40 (Mark A. Hall ed., 1999).

118. For excellent discussions of how physicians can talk about these issues directly with patients, see Wendy Levinson et al., Resolving Disagreements in the Patient-Physician Relationship: Tools for Improving Communication in Managed Care, 282 JAMA 1477, 1477 (1999); Miller \& Horowitz, supra note 105 . 
incentive and perhaps the direction in which it potentially biases decisions, leaving to individuals the decision of whether they wish to seek more information and whether and to what extent to take this information into account when making decisions and evaluating courses of action.

This approach attempts to provide as much information as most people are likely to want, at the point at which they need it, and it has sufficient flexibility to allow people to learn more as their understanding and information needs change. It also attempts to meet the major objectives of disclosure while avoiding the major objections. Nevertheless, this is merely a preliminary sketch and therefore leaves many issues of implementation unaddressed. How well this and other approaches actually succeed in these ambitions, and what impact these disclosures will have, remains to be seen.

Whichever approach is taken, incentive disclosure should not be mandated through liability rules. Because the managed care industry has demonstrated its willingness to disclose physician incentives, regulation, or perhaps only ethical guidelines and voluntary industry standards, are sufficient to achieve widespread compliance. Prescriptive disclosure standards provide notice and consistency, and they permit a level of nuance and flexibility that cannot be achieved through a liability regime. However, regulators need to be sensitive to the complexities and variations in physician incentives and the need for experimentation in disclosure methods. Regulators should also work to overcome the view that legal compliance is in tension with conveying useful information that consumers and patients can expect to understand. Only then can we hope that incentive disclosure will be used to advance broader public understanding (even among law professors), that everyone has a stake in pursing health care cost containment, and that no single method of doing so is superior to all of the others. 


\section{APPENDIX A}

The following is a letter sent to members of the Harvard Pilgrim Health Care Plan by its medical director in 1998. The arrangements it describes may not still be in effect.

\section{How We Pay Our Doctors}

Harvard Pilgrim Health Care believes it is important for our members to understand all aspects of their health care and coverage. We believe we have an obligation to provide information about the way we pay doctors to ensure that our members are well-informed, and would like to answer some questions that have recently been raised about this issue. The following explains the principles and methods that determine how physicians are paid at HPHC.

\section{PRINCIPLES}

At Harvard Pilgrim Health Care, we have relationship[s] with our 18,000 doctors who practice in a variety of settings, including health centers, independently-owned and organized medical groups, hospital-affiliated and individual community practices. All these relationships mean that our patients are cared for by doctors who are paid in many different ways. Although there may be variation in the specifics of how we pay doctors, HPHC abides by some basic and fundamental principles. These principles are important to consider as you think about how your doctor might be paid for the services he or she provides to, or arranges for, you.

The ways we pay our doctors encourage and reward preventive care and the early treatment and active management of acute and chronic illnesses. This means that our doctors have a financial incentive to give all of the care necessary to keep patients healthy and help prevent more serious and costly illness later on.

- The methods we use to pay our doctors are designed to help improve clinical quality, access to services and patient communication while also attempting to lower overall costs of care. We believe we owe it to our members to keep premiums and out-of-pocket expenditures as low as possible so that members can afford to get health care. We also recognize the potential harm of doing unnecessary tests or procedures, and believe in devoting time and effort to deciding when they are truly needed.

- Our pay programs are intended to encourage collaboration and ensure that no individual doctor has an incentive to provide more or less care than necessary. We believe that doctors can deliver services more effectively by working with other doctors in various ways to manage the health care needs of their patients. Patients benefit from the reduced costs and improved 
quality of well-coordinated care. Therefore, although groups of doctors with whom we are affiliated have financial incentives to manage the total care of their members, individual doctors will not directly benefit financially if a specific test is not ordered or a referral not made for any individual patient.

- We encourage our affiliated doctors to discuss appropriate treatment options with their patients even in the rare instance in which a recommended treatment is not part of their insurance coverage. We have never had, nor will we ever have, so-called "gag rules." This means that members should feel confident that our doctors are free to discuss possible treatments for a particular condition or illness, regardless of whether it is a covered benefit.

- We believe that an important part of our relationship with doctors is to set goals so that we can measure how well they are caring for our patients. We, therefore, include a component in our compensation programs that rewards the provision of preventive care and achievement of high member satisfaction.

PAYMENT METHODS ... [Following this is a description of salary, capitation, withhold pools, and stop-loss protection.] 


\section{APPENDIX B}

The following is excerpted from Haavi Morreim, To Tell the Truth: Disclosing the Incentives and Limits of Managed Care, 3 AM. J. MANAGED CARE 35, 36-37 (1997).

Many people who choose managed care plans, or who are enrolled by their employers, are concerned about the cost of health care. They want to receive all the care they need, but they don't want to see premiums and out-of-pocket costs rise right through the ceiling. We share this concern, and would like to explain to you the ways we try to keep costs down.

\section{Health Care Costs Are Skyrocketing}

In the U.S., the money we spend on health care has risen steadily for decades-much faster than the rate of inflation. Today, about 15 cents out of every dollar is [sic] spent on health care. The quality of American health care is the envy of the world, but we must keep the cost under control, or fewer and fewer of us will be able to afford it.

\section{It's Your Money}

If you receive health coverage as an employment benefit, it's easy to suppose that your employer, rather than yourself, pays for your health care. Wrong. You are paying, whether you realize it or not. The bottom line is, your employer pays a certain amount to keep you working. Some of it goes into one of your "pockets" as your wages, and some of it goes into your other pocket for benefits. In either pocket, it's still your money. The more your employer has to spend for health care, the less is left to increase your wages or other benefits. Besides that, you pay part of the monthly premium for your health plan. That goes up when premiums go up. And if you pay copayments at the time you actually receive health care-whether to see the doctor or stay in the hospital or buy medicines-those costs rise, too.

\section{Fairness to You Requires Honoring the Limits for Everyone}

When you buy your health plan, it's with the understanding that you will receive certain benefits in exchange for your premium. In an HMO, it's also true that we must provide all the care that everyone in the plan needs, within a fixed budget every year. There's plenty of money in that budget to cover all the care that subscribers need. But if a health plan doesn't draw limits on what it covers, either it will run out of money, or premiums will rise out of sight.

Once those limits are drawn, they have to be honored. It would be unfair to everyone if we let some people have more benefits than they actually bought. For instance, if one of your fellow subscribers wanted us to pay for a face-lift, it would be unfair to you if we said yes. You bought the plan with the understanding that it has some limits, and if we play favorites and ignore those limits for some subscribers, it violates everyone's trust. It's our obligation to be careful with your money, so that your health care is there when you need it. 


\section{All Health Plans Enforce Limits; But Not All Plans Tell their Subscribers}

As you can understand, insurers and HMOs must make sure that resources are used wisely. Virtually all of them have utilization controls, for example, to ensure that patients receive necessary services, but not all sorts of tests and treatments they don't need. And most HMOs have incentives that encourage physicians to be prudent about what they order. In fact, the Federal law that regulates HMOs actually permits, even expects, them to have some incentives. But not all health plans are willing to be honest with their subscribers. Many plans say nothing about them, and some actually forbid their physicians from telling patients anything that might make them think poorly of the planincluding information about limits on care.

At Healthplan, we believe that the more you know about your health plan, the more you can be a full partner with us, and the better we can serve you. You know what it is to work within a budget, because you do the same thing every day as you care for your family within the income you earn. We have to do the same, and we know you understand what that means.

\section{It's Not Just Costs, It's Quality}

It's easy to focus on costs, but there's a flip side of that coin: quality. The more careful we are not to waste your money, the more funds are left to do more for you. Last year, for instance, we added several services, like extra home health visits for some of our elderly patients and for women with high-risk pregnancies. Beyond that, as we carefully track which services are provided for which patients, and pay attention to what works and what doesn't, we are learning more and more about what's the best care. Needless medical tests and treatments don't just waste money, they can sometimes do a lot of damage. And on the other side, not providing enough care can cost a lot more money in the long run, if someone gets sicker because he or she wasn't treated right the first time.

\section{So How Do We Keep the Lid on Health Care Costs?}

Here at Healthplan, we arrange for your care by entering into contracts with physician group practices. Some of these groups have only primary care physicians like family doctors and pediatricians; other groups include specialists like cardiologists (heart doctors) and pulmonologists (lung doctors). Because each group is free to pay its doctors and deliver care in whatever way it wants, there isn't any one system that applies to all of them. But most of them use two basic approaches: utilization management, and incentives.

\section{Utilization Management}

In order to make sure that all the people who subscribe to Healthplan receive the same high quality of care, we have developed guidelines that we ask our physician groups to follow. These guidelines help identify what sort of care is actually needed, in which situations. Sometimes they will say that you 
shouldn't receive some things you might be expecting. We don't prescribe antibiotics for the common cold, for instance-they don't do any good at all, and they can actually do some harm.... These guidelines are not hard-and-fast rules. People are not all alike, and even the best guidelines sometimes won't quite fit a particular patient's needs. At Healthplan, your physician has the discretion to make sure you get the care you need. Sometimes, in the more complicated situations, we also use a case manager. ...

\section{Incentives.}

The second major way we contain costs is to encourage the cooperation of our physicians. After all, guidelines don't do much good if they gather dust on a shelf. As we said just above, each physician group is free to pay its doctors in whatever way it wants, so there isn't any single incentive system that applies to all of them. We'll describe the major ones here. To find out the details for your situation, you'll need to talk to the people at your own medical group.

In order to understand how our physician-incentives work, you need first to understand that economic incentives are everywhere. They can't be avoided. Suppose you hire a fellow to paint your house. If you pay him by the hour, he has an incentive to take his time. Or if you pay him a fixed fee to paint the whole house, he has an incentive to hurry so he can get on to the next job. But - and this is important! - just because he has this or that incentive doesn't mean he'll do a bad job. It only means that, that no matter how you pay someone for a service, there will be incentives in one direction or another.

That's true of physicians, just like everyone else. Before HMOs came along, physicians were usually paid a separate fee for each service they performed. That system tended to reward physicians for performing lots of services. Gradually the medical profession began to deliver care that sometimes goes beyond what patients really need. As a result, a fair amount of "fat" has grown up in the system, and physicians now need to figure out where they've been doing too much. Doing too much doesn't just waste money. It can hurt patients. But deciding what's "too much" and what's "just right" takes time and effort. Incentive systems can reward physicians for drawing this line carefully.... [Following this is a description of salary, capitation, and withhold pools.]

\section{Incentives for Patients}

Most HMOs only have incentives for physicians. But here at Healthplan, we believe that the patient is the most important member of the team. Your health, your health care, and your money are all at stake. So we think it makes sense to reward patients for thinking prudently about their care... . The details are in the special brochure that came with your membership packet. 